\title{
Gas exchange and photosynthetic light response curves in nematode-infected tomato plants treated with Thuya occidentalis
}

\author{
Thaísa Muriel Mioranza ${ }^{1 *}$, Adriano Mitio Inagaki ${ }^{2}$, Mônica Anghinoni Müller ${ }^{3}$, José Renato Stangarlin ${ }^{2}$, \\ Vandeir Francisco Guimarães ${ }^{2}$, Jeferson Klein ${ }^{4}$, Odair José Kuhn ${ }^{2}$ \\ ${ }^{1}$ Department of Agronomy, State University of Maringá - UEM, Maringá, Paraná State, Brazil \\ ${ }^{2}$ Department of Agronomy, Western Paraná State University - Unioeste, Marechal Cândido Rondon, Paraná State, \\ Brazil \\ ${ }^{3}$ Department of Agronomy, Federal University of Paraná - UFPR, Curitiba, Paraná State, Brazil \\ ${ }^{4}$ Anhanguera College, Cascavel, Paraná State, Brazil
}

\section{*Corresponding author: thaisamioranza@hotmail.com}

\section{Abstract}

The use of homeopathic formulations on plants may cause changes in plant metabolism and result in disease control by inducing resistance. This work aimed to study the physiological responses of tomato plants infected with nematode (Meloidogyne incognita) and treated with highly diluted preparations of Thuya occidentalis, a homeopathic remedy. The different treatments included $T$. occidentalis $6 \mathrm{CH}, 24 \mathrm{CH}$, and $50 \mathrm{CH}$ (Centesimal Hahnemanian), a water control (with nematode and without treatment), and an absolute control (no treatment and no nematode). The assay was conducted in a greenhouse using a randomized block design with four replications. Gas exchange parameters were measured at specific times before and after nematode inoculation. Photosynthetic rate, stomatal conductance, transpiration, leaf internal $\mathrm{CO}_{2}$ concentration, and leaf temperature were measured at various photosynthetic photon flux densities. No significant difference was found in the different gas exchange specific measure parameters between the treatments. Untreated infected plants showed an increase in net photosynthesis and in the carboxylation capacity, as shown by the light response curve. Treatment with $T$. occidentalis $24 \mathrm{CH}$ inhibited the increase in $\mathrm{CO}_{2}$ fixation in tomato plants inoculated with $M$. incognita, leading to a similar behavior as healthy plants, independently of the photon density.

Keywords: alternative control, homeopathy, photosynthetic photon flux density, root-knot nematode, Solanum lycopersicum L.

\section{Introduction}

Homeopathy is a system of alternative medicine that uses highly diluted substances in treatment protocols, and the use of homeopathic substances in agriculture has been increasingly growing, especially in the field of plant protection (Toledo et al., 2011). According to the viewpoint of homeopathy, illness is the consequence of loss of homeostasis, and although many studies have been performed in this field, little is known about the physiological effects of homeopathic substances in treated plants (Bonato, 2007).

Plants infected with the nematode Meloidogyne spp. exhibit formation of galls (swellings) on the roots, resulting in hyperplasia and hypertrophy of cells around the nematode feeding site. As a consequence, the vascular elements are interrupted and deformed, preventing the normal translocation of water and nutrients to the canopy plant and interfering with plant growth (Castagnone-Sereno et al., 2013). Furthermore, when infecting a host plant, the nematode rapidly breaks physiological routes involving most of the major processes, such as respiration, photosynthesis, nutrient translocation, and hormone and water balance (Karssen and Moens, 2006).
Some studies have focused on controlling nematode infections in tomato plants (Solanum lycopersicum L.) using highly diluted substances (Sukul et al., 2013; Swarowsky et al., 2014; Mioranza et al., 2017), which may activate plant defense mechanisms and induce resistance. For instance, Mioranza et al. (2017) studied the use of Thuya occidentalis in the control of $M$. incognita in tomato plants, and observed that the dynamization of $100 \mathrm{CH}$ can reduce the number of nematodes, while the $24 \mathrm{CH}$ and $200 \mathrm{CH}$ improved the growth parameters of plants and increased the activity of some plant defense related enzymes, such as peroxidase and phenylalanine ammonia-lyase.. Messchimidt (2013) found that plants infected with $M$. javanica have increase in photosynthesis until the 60 days after inoculation and after that, there was a reduction. Sarkar et al. (2017) used ultrahigh dilution of Mercuric chloride $(200 \mathrm{CH})$ in Vigna unguiculata (L.) and verified that the treatment promotes improve of photosynthesis. However, there is no study about the leaf gas exchange and their parameters in the interaction plant-nematode-high diluted substances. Therefore, to understanding this interaction, the aim of this study was to evaluate the physiological responses, as gas 
exchange, of tomato plants infected with Meloidogyne incognita (Kofoid and White) Chitwood. when treated with highly diluted solutions of the homeopathic remedy Thuya occidentalis.

\section{Results}

\section{Gas exchange and infestation level}

No significant differences were found in gas exchange parameters between homeopathic and control treatments before inoculation and five, eight, and 13 days after inoculation (ANOVA, $p \leq 0.05$ ) (data not shown). The same results were observed to nematode infestation level, with no differences among the treatments (Table 1).

\section{Photosynthetic response curves to treatment with $T$. occidentalis $6 \mathrm{CH}$}

To the treatment $T$. occidentalis $6 \mathrm{CH}$ no significant relationship was found with PPFD response curves, showing that this treatment did not influence the $\mathrm{CO}_{2}$ net assimilation rate, which was statistically similar to that of the controls (healthy plants) (Figure 1). According to the exponential curve, the $\mathrm{CO}_{2}$ saturated net photosynthetic rate occurred at a high PPFD concentration (about 1200 $\mu \mathrm{mol} \mathrm{m} \mathrm{s}^{-1}$ PPFD).

In relation to the stomatal conductance $\left(g_{s}\right)$, the $6 \mathrm{CH}$ treatment showed a lower average than the water and absolute controls, regardless of the photon density (Figure 1B). This shows that plants treated with $T$. occidentalis $6 \mathrm{CH}$ tended to have stomatal closure $\left(0.27 \mathrm{~mol} \mathrm{~m}^{-2} \mathrm{~s}^{-1}\right)$.

The internal $\mathrm{CO}_{2}$ concentration $(\mathrm{Ci})$ showed an inverted exponential behavior curve, decreasing from $0 \mu \mathrm{mol} \mathrm{m} \mathrm{m}^{-2} \mathrm{~s}^{-1}$ PPFD onwards and beginning to stabilize at about $900 \mu \mathrm{mol}$ $\mathrm{m}^{-2} \mathrm{~s}^{-1}$. Concentrations between 900 and $1800 \mu \mathrm{mol} \mathrm{m} \mathrm{m}^{-2} \mathrm{~s}^{-1}$ correspond to a period of large stomatal aperture, affecting $\mathrm{CO}_{2}$ diffusion. The $\mathrm{Ci}$ average of plants treated with $T$. occidentalis $6 \mathrm{CH}$ was lower $\left(338.73 \mu \mathrm{mol} \mathrm{CO}_{2} \mathrm{~mol}^{-1}\right)$ than those of the two controls ( 350.49 and $352.06 \mu \mathrm{mol} \mathrm{CO}_{2} \mathrm{~mol}^{-}$ $\left.{ }^{1}\right)$, probably due to a lower stomatal opening rate. Nevertheless, this did not seem to interfere with $\mathrm{CO}_{2}$ fixation (Figure 1C).

The PPFD response curve for leaf transpiration rate $(E)$ showed an exponential behavior, with $E$ increasing with photon flux density. Plants treated with $T$. occidentalis $6 \mathrm{CH}$ had a lower $E$ average $\left(3.88 \mathrm{mmol} \mathrm{H}_{2} \mathrm{O} \mathrm{m}^{-2} \mathrm{~s}^{-1}\right)$ than the absolute $\left(4.76 \mathrm{mmol} \mathrm{H}_{2} \mathrm{O} \mathrm{m}^{-2} \mathrm{~s}^{-1}\right)$ and water $\left(4.88 \mathrm{mmol} \mathrm{H}_{2} \mathrm{O}\right.$ $\mathrm{m}^{-2} \mathrm{~s}^{-1}$ ) control treatments (Figure 1D). The lower water loss of plants treated with $T$. occidentalis $6 \mathrm{CH}$ may be due to stomatal closure (Figure 1B).

Intrinsic water use efficiency (IWUE) was stable at approximately $450 \mu \mathrm{mol} \mathrm{m} \mathrm{m}^{-2} \mathrm{~s}^{-1}$ (PPDF), which means that stomatal opening occurred at the same time as the increase in $\mathrm{CO}_{2}$ fixation from 450 to $1800 \mu \mathrm{mol} \mathrm{m} \mathrm{s}^{-1}$ (PPFD) (Figure 1F). A significant difference in IWUE was found between treatments. Irrespectively of the PPFD level, plants treated with $T$. occidentalis $6 \mathrm{CH}$ had a higher IWUE $(23.05)$ than the water and absolute controls ( 16.36 and 15.07 , respectively). This confirms the stomatal closure resulting from this homeopathic treatment, shown in Figure 1B.

The WUE ratio, i.e. the ratio between liquid $\mathrm{CO}_{2}$ uptake rate and leaf transpiration, provides the relative value of
$\mathrm{H}_{2} \mathrm{O}$ vapor loss for each $\mathrm{CO}_{2}$ set (Figure $1 \mathrm{E}$ ). The WUE ratio followed a hyperbolic model with a maximum at approximately $800 \mu \mathrm{mol} \mathrm{m} \mathrm{m}^{-2} \mathrm{~s}^{-1}$ (PPFD), slightly decreasing after that until $1800 \mu \mathrm{mol} \mathrm{m} \mathrm{m}^{-2}$. This trend matches the observed exponential increase in water loss ( $E$; Figure 1D). No significant relationship was found between plant treatments and PPFD in terms of WUE (Figure 1D). However, when averages were compared, water use efficiency was higher in plants treated with $T$. occidentalis $6 \mathrm{CH}$. This is probably due to lower $g_{s}$ values in these plants when compared to the control treatments, directly influencing leaf transpiration rate (Figures 1B and 1D).

Average carboxylation capacity $(A C i)$ was not significantly different between treated plants and controls (Figure 1G). The exponential regression model revealed that $A C I$ stabilized at about $1400 \mu \mathrm{mol} \mathrm{m} \mathrm{s}^{-1}$ (PPFD) and reached a maximum carboxylation capacity of 0.07 (ACi) at $1800 \mu \mathrm{mol}$ $\mathrm{m}^{-2} \mathrm{~s}^{-1}$.

Leaf temperature (Tleaf) showed a linear behavior, decreasing from 0 to $1800 \mu \mathrm{mol} \mathrm{m} \mathrm{m}^{-2}$ (PPFD) (Figure $1 \mathrm{H}$ ). This decrease is due to the increase in leaf transpiration rate, which causes cooling of the leaf. Temperature was more stable in the absolute control treatment than in those with an increase in photon flow densities.

\section{Photosynthetic response curves to treatment with $T$. occidentalis $24 \mathrm{CH}$}

The PPFD response curve of the $\mathrm{CO}_{2}$ liquid uptake rate $(A)$ in plants treated with $T$. occidentalis $24 \mathrm{CH}$ (Figure 2) was different from that observed in plants which received the $6 \mathrm{CH}$ treatment (Figure 1A). There was a significant relationship in terms of $A$ between treated plants and PPFD. The exponential adjusted model revealed that saturation of the net $\mathrm{CO}_{2}$ absorption occurred at around $1000 \mu \mathrm{mol} \mathrm{m} \mathrm{m}^{-2} \mathrm{~s}^{-1}$ (PPFD). The light compensation point was lower for healthy plants $\left(16.68 \mu \mathrm{mol} \mathrm{m} \mathrm{m}^{-2} \mathrm{~s}^{-1}\right)$ than for those treated with $T$. occidentalis $24 \mathrm{CH}\left(18.31 \mu \mathrm{mol} \mathrm{m} \mathrm{m}^{-2}\right)$, whereas the water control showed a higher light compensation point (23.89 $\mu \mathrm{mol} \mathrm{m} \mathrm{m}^{-2}$ ).

Plants treated with water showed higher photosynthetic rates at $480 \mu \mathrm{mol} \mathrm{m} \mathrm{m}^{-2} \mathrm{~s}^{-1}$ (PPFD) than plants treated with $T$. occidentalis $24 \mathrm{CH}$, but not different from the control. When densities of 960,1440 , and $1800 \mu \mathrm{mol} \mathrm{m} \mathrm{m}^{-2} \mathrm{~s}^{-1}$ photon flux were used, the water control had higher averages than the other treatments (Figure 2A). Regression analysis showed that plants treated with water, $T$. occidentalis $24 \mathrm{CH}$, and untreated not inoculated plants showed maximum $\mathrm{CO}_{2}$ net uptake rates of 22.09, 18.88, and $18.75 \mu \mathrm{mol} \mathrm{CO} \mathrm{Cm}^{-2} \mathrm{~s}^{-1}$, respectively.

The observed maximum $\mathrm{CO}_{2}$ net uptake rates were related to stomatal conductance $\left(g_{s}\right)$. Although no significant relationship was found between treatments and PPFD in terms of $g_{s}$, the highest average stomatal conductance $(0.60$ $\mathrm{mol} \mathrm{m} \mathrm{m}^{-1}$ ) was found in plants treated with water (Figure 2B). Control plants and plants treated with $T$. occidentalis $24 \mathrm{CH}$ showed the lowest average $\left(0.38\right.$ and $\left.0.35 \mathrm{~mol} \mathrm{~m}^{-2} \mathrm{~s}^{-1}\right)$. The $\mathrm{Ci}$ curve showed an inverse exponential behavior, and the responsive averages to the behavior of $g_{s}$ variable. Plants treated with water had a higher average internal $\mathrm{CO}_{2}$ concentration $\left(359.58 \mu \mathrm{mol} \mathrm{CO} \mathrm{mol}^{-1}\right.$ ) than other plants, probably due to a greater stomatal opening. The PPFD 
Table 1. Infestation level of tomato inoculated with Meloidogyne incognita and treated with Thuya occidentalis.

\begin{tabular}{ll}
\hline Treatments & Infestation level \\
\hline$T$. occidentalis $6 \mathrm{CH}$ & $827 \mathrm{a}$ \\
$T$. occidentalis $24 \mathrm{CH}$ & $1106 \mathrm{a}$ \\
T. occidentalis $50 \mathrm{CH}$ & $1001 \mathrm{a}$ \\
$\mathrm{H}_{2} \mathrm{O}$ & $869 \mathrm{a}$ \\
\hline $\mathrm{CV}(\%)$ & 13.2 \\
\hline
\end{tabular}

In the column, means followed for the same letter do not differ from each other by Tukey's HSD test (P $\leq 0.05)$.
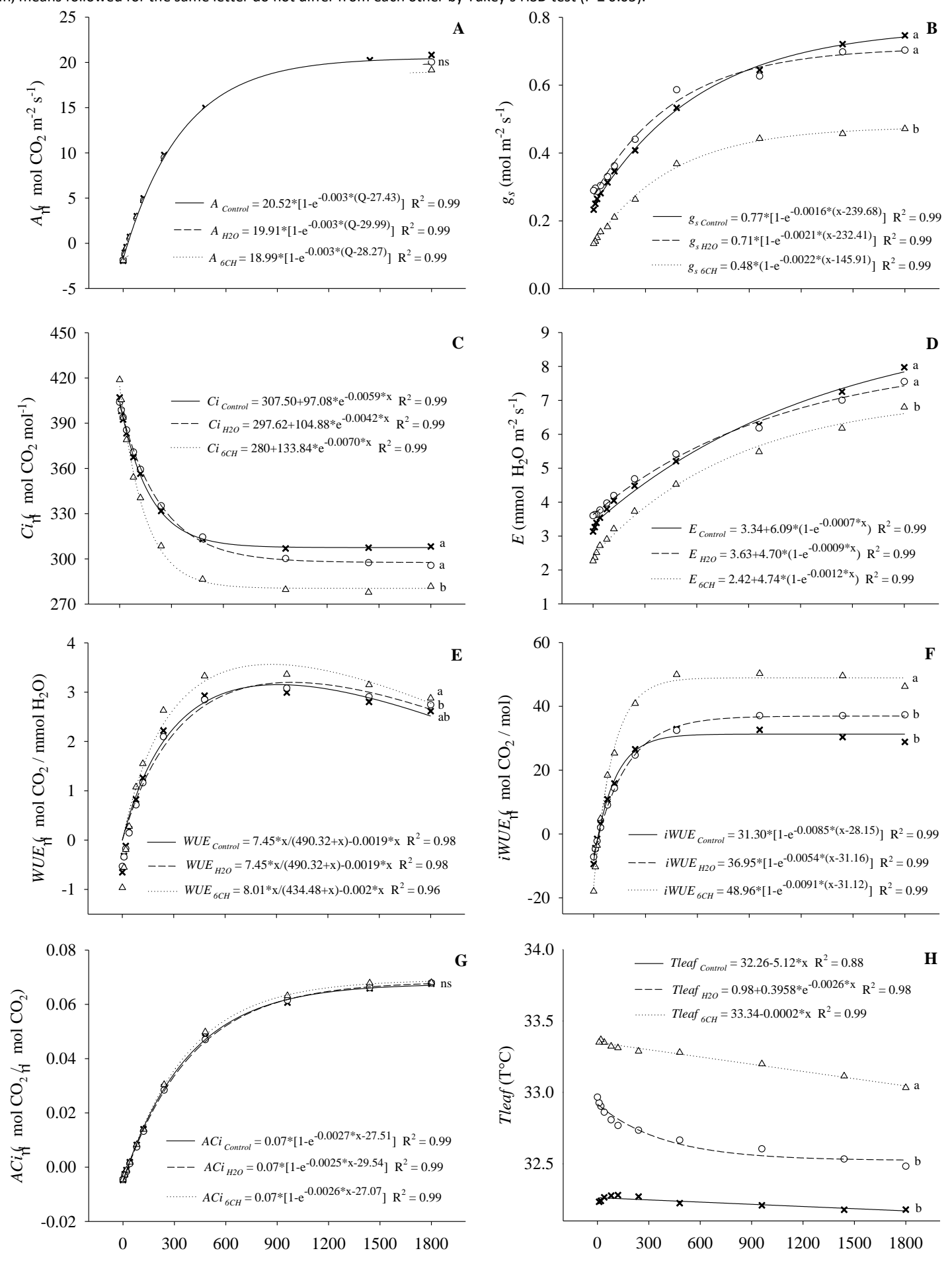

Photosynthetic photon flux density $\left(\mu \mathrm{mol} \mathrm{m} \mathrm{m}^{-2}\right)$

Photosynthetic photon flux density $\left(\mu \mathrm{mol} \mathrm{m} \mathrm{m}^{-2}\right.$ )

Fig 1. $\mathrm{CO}_{2}$ net assimilation rate (A), stomatal conductance (B), internal $\mathrm{CO}_{2}$ concentration (C), transpiration rate (D), water use efficiency (E), intrinsic water use efficiency $(F)$ carboxylation capacity $(G)$ and leaf temperature $(H)$ of healthy tomato plants (control), inoculated with Meloidogyne incognita and untreated $\left(\mathrm{H}_{2} \mathrm{O}\right)$ and inoculated and treated with Thuya occidentalis $6 \mathrm{CH}$. At the end of the curved: $n s=$ not significant, $a, b$ or $c=$ Different by Tukey's HSD test $(p \leq 0.05)$. 

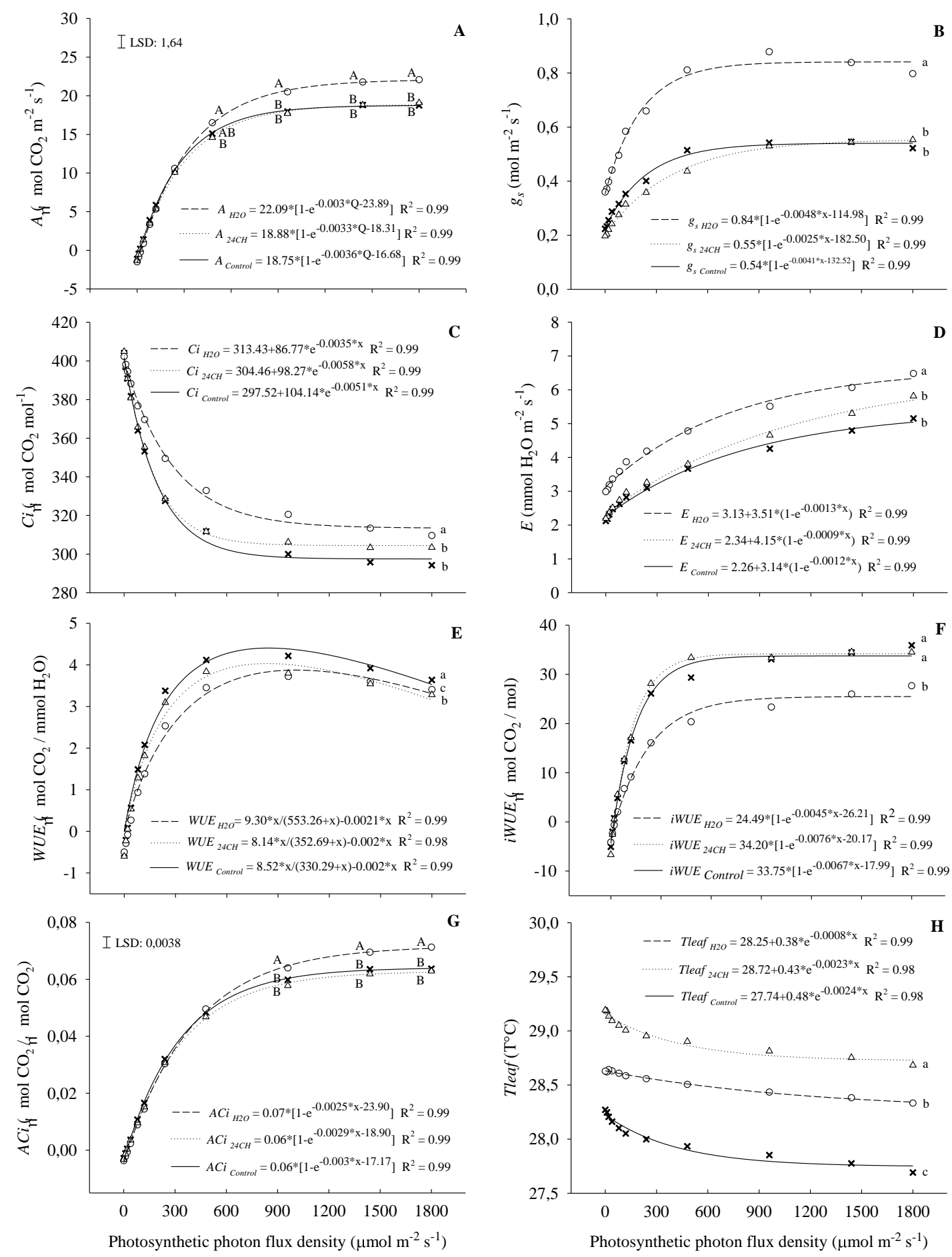

Fig 2. $\mathrm{CO}_{2}$ net assimilation rate (A), stomatal conductance (B), internal $\mathrm{CO}_{2}$ concentration (C), transpiration rate (D), water use efficiency (E), intrinsic water use efficiency (F) carboxylation capacity (G) and leaf temperature (H) of healthy tomato plants (control), inoculated with Meloidogyne incognita and untreated $\left(\mathrm{H}_{2} \mathrm{O}\right)$ and inoculated and treated with Thuya occidentalis $24 \mathrm{CH}$. At the end of the curved: $n s=$ not significant, $a, b$ or $c=$ Different by Tukey test $(p \leq 0.05)$. LSD = least significant difference. 

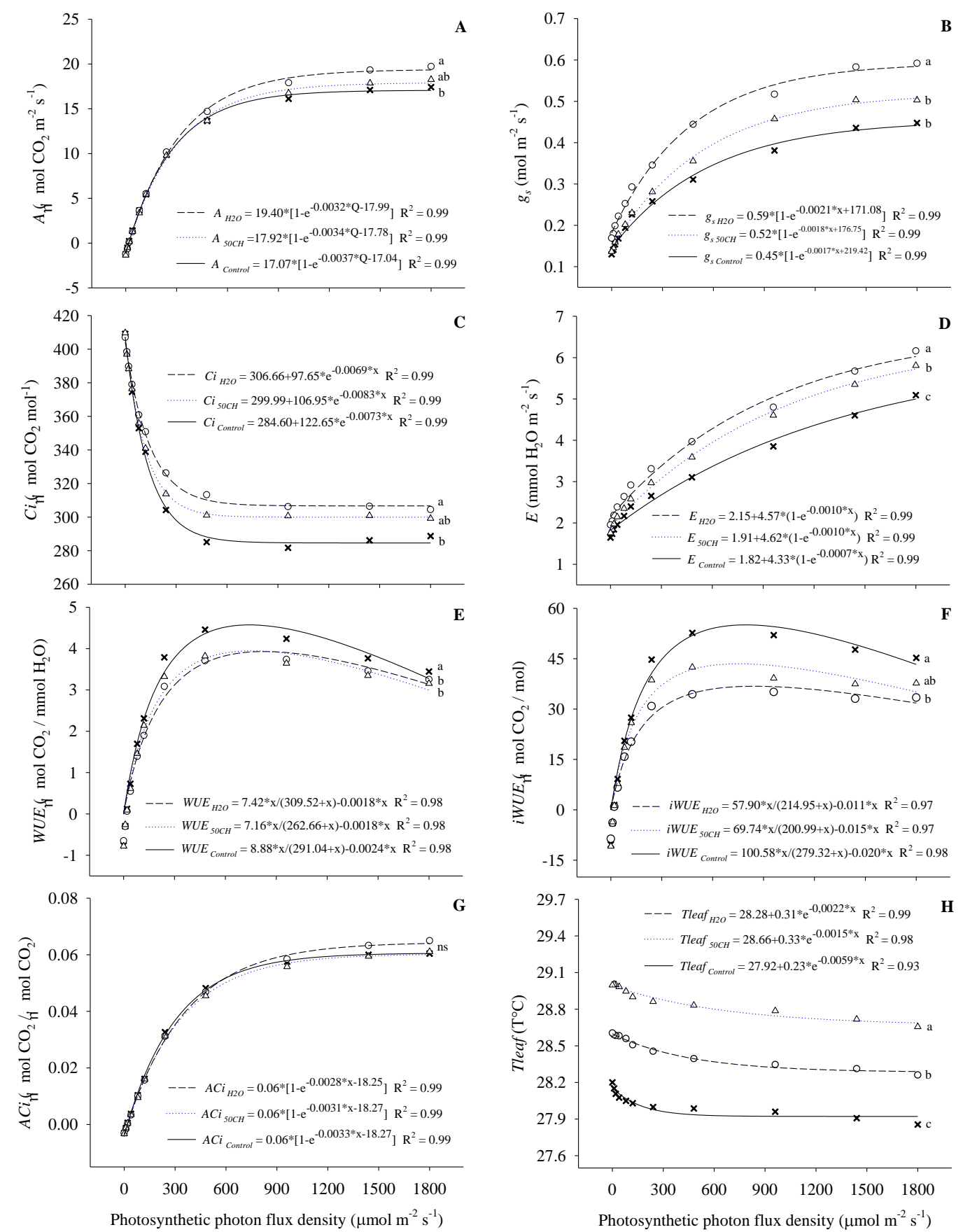

Fig 3. $\mathrm{CO}_{2}$ net assimilation rate (A), stomatal conductance (B), internal $\mathrm{CO}_{2}$ concentration (C), transpiration rate (D), water use efficiency $(E)$, intrinsic water use efficiency $(F)$ carboxylation capacity $(G)$ and leaf temperature $(H)$ of healthy tomato plants (control), inoculated with Meloidogyne incognita and untreated $\left(\mathrm{H}_{2} \mathrm{O}\right)$ and inoculated and treated with Thuya occidentalis $50 \mathrm{CH}$. At the end of the curved: $n s=$ not significant, $a, b$ or $c=$ Different by Tukey test $(p \leq 0.05)$.

response curve for leaf transpiration rate $(E)$ was also higher in these plants (Figures $2 \mathrm{C}$ and 2D). Plants treated with water lost an average of $4.28 \mathrm{mmol} \mathrm{H}_{2} \mathrm{O} \mathrm{m} \mathrm{m}^{-2}(E)$, which was more than the loss in transpiration of plants treated with $T$. occidentalis $24 \mathrm{CH}$ and the absolute control (healthy plants) (3.44 and $3.23 \mathrm{mmol} \mathrm{H}_{2} \mathrm{O} \mathrm{m} \mathrm{m}^{-2} \mathrm{~s}^{-1}$, respectively). Healthy plants showed a more efficient water use with an average value of 2.10 , which was higher than the WUE of plants treated with $T$. occidentalis $24 \mathrm{CH}$ (1.87) and with water (1.72) (Figure 2E). This means that, although plants infected with nematodes and treated with water fix more $\mathrm{CO}_{2}$ than plants receiving other treatments, they lose more water vapor. Healthy plants, without nematode inoculation, lose less water to $\mathrm{CO}_{2}$ fixation. These plants limit the photosynthetic activity at lower photon flux densities, between 0 and $300 \mu \mathrm{mol} \mathrm{m} \mathrm{m}^{-1}$ (Figure 2A). Although no significant relationship was found between PPFD and treatment in terms of WUE, the response curve for leaf transpiration rate in water treated plants increased in all photon flux density levels, reducing the average WUE (Figures 2D and 2E).

The intrinsic water use efficiency (IWUE) achieved stability at about $600 \mu \mathrm{mol} \mathrm{m} \mathrm{m}^{-2} \mathrm{~s}^{-1}$ (PPFD) in absolute control plants and plants treated with $T$. occidentalis $24 \mathrm{CH}$. Infected plants 
treated with water only, stabilized at $900 \mu \mathrm{mol} \mathrm{m} \mathrm{s}^{-2}$ (PPFD) (Figure 2F). Regression analysis revealed that the maximum IWUE of water control plants was 24.49, with an average of 11.63 , which was lower than the average IWUE of plants treated with $T$. occidentalis $24 \mathrm{CH}$ (18.07) and with the absolute control (19.93) (maximum values of 34.20 and 33.75 , respectively). $T$. occidentalis $24 \mathrm{CH}$ prevented negative effects of nematode infection on the stomatal opening behavior, altering the plant's metabolism so that the stomatal behavior remains similar to that of healthy plants.

The $A C i$ ratio, which relates photosynthesis $(A)$ with the internal concentration of $\mathrm{CO}_{2}$ in the mesophyll $(C i)$, shows the in vivo estimated carboxylation efficiency of the rubisco enzyme (Figure 2G). A significant relationship between PPFD and treatments was found for photon flux densities of 960, 1440 and $1800 \mathrm{mmol} \mathrm{m}^{-2} \mathrm{~s}^{-1}$, whereby infected plants treated with water had higher carboxylation capacity. Despite the fact that the homeopathic treatment with $T$. occidentalis $24 \mathrm{CH}$ leads to higher WUE and IWUE averages than the treatment with water, the $\mathrm{ACi}$ ratio demonstrates that the ability to fix $\mathrm{CO}_{2}$ did not follow the trend of the other ratios (WUE and IWUE). This suggests that, in the present study, $\mathrm{CO}_{2}$ fixation in tomato plants was only dependent on the inoculation with $M$. incognita, since the use of $T$. occidentalis $24 \mathrm{CH}$ inhibited the effect of the inoculation. Average leaf temperature (Tleaf) was, similarly to the results of the $6 \mathrm{CH}$ treatment, higher in plants treated with $T$. occidentalis $24 \mathrm{CH}$ $\left(28.98{ }^{\circ} \mathrm{C}\right)$ than in water treated plants $\left(28.54{ }^{\circ} \mathrm{C}\right)$ and in untreated plants $\left(28.03{ }^{\circ} \mathrm{C}\right)$. Nevertheless, no significant relationship was found between plant treatments and light densities (PPFD).

\section{Photosynthetic response curves to treatment with $T$. occidentalis $50 \mathrm{CH}$}

No significant relationship was found between treatments and PPFD in terms of $A, g_{s}, C i, E$, WUE, IWUE, A/Ci and Tleaf in plants treated with $T$. occidentalis $50 \mathrm{CH}$. However, a significant difference was found in average values between treatments (Figure 3).

The response curve of the $\mathrm{CO}_{2}$ net assimilation rate under different PPFD in plants treated with $T$. occidentalis $50 \mathrm{CH}$, as well as in the two controls, followed the same trend as the curve of $T$. occidentalis $24 \mathrm{CH}$ treated plants (Figure 2A). Water treated plants reached a net assimilation rate of $19.40 \mu \mathrm{mol} \mathrm{CO} \mathrm{CO}_{2}^{-2} \mathrm{~s}^{-1}$ and a light compensation point of $17.99 \mu \mathrm{mol} \mathrm{m} \mathrm{m}^{-2} \mathrm{~s}^{-1}$, as revealed by the adjusted exponential model (Figure $3 \mathrm{~A}$ ). The absolute control had a lower rate, with a maximum of $17.07 \mu \mathrm{mol} \mathrm{CO}_{2} \mathrm{~m}^{-2} \mathrm{~s}^{-1}$ and a compensation point of $17.04 \mu \mathrm{mol} \mathrm{m} \mathrm{m}^{-2} \mathrm{~s}^{-1}$, which was not different from the average assimilation rate of nematode infected plants treated with $T$. occidentalis $50 \mathrm{CH}$.

Net photosynthesis, internal $\mathrm{CO}_{2}$ concentration, and leaf transpiration rate related directly to stomatal conductance (Figures 3A, 3C, 3D, and 3B). As was seen in the treatments with $T$. occidentalis $6 \mathrm{CH}$ and $24 \mathrm{CH}$ (except for the results shown in Figure $1 \mathrm{~A}$ ), treatments that showed higher $g_{s}$ also showed a greater $\mathrm{CO}_{2}$ diffusion $(\mathrm{C} i)$, and thus, higher net $\mathrm{CO}_{2}$ assimilation $(A)$ and leaf transpiration rate $(E)$. T. occidentalis seems to inhibit the effect of the nematode on the photosynthesis and may lead to a low plant production of photo assimilates, which are used by the nematodes.
The response curves of the WUE and IWUE ratios (Figures $3 E$ and $3 \mathrm{~F}$ ) were similar to those of plants treated with $T$. occidentalis $24 \mathrm{CH}$ (Figures $2 \mathrm{E}$ and $2 \mathrm{~F}$ ), showing that healthy plants, under different PPFD, have higher water use efficiency and intrinsic water use efficiency.

Although significant differences were found in $A$ and $C i$ between treatments (Tukey's test, $\mathrm{P} \leq 0.05$ ), the $A / C i$ ratio did not show significant differences, neither between treatments nor in the interaction between treatments and PPFD levels (Figure 3G). However, regression analysis of the average PPFD within each treatment resulted in an adjusted exponential equation with the same $\mathrm{ACi}$ maximum point (0.06) for all three treatments.

Tomato plants treated with $T$. occidentalis $6 \mathrm{CH}, 24 \mathrm{CH}$, and $50 \mathrm{CH}$ always achieved higher average leaf temperature (Tleaf) than plants receiving other treatments (Figures $1 \mathrm{H}$, $2 \mathrm{H}$ and $3 \mathrm{H}$ ). Regression analysis showed that the best model suggested that leaf temperature decreases as photon flow density increases (Figure $3 \mathrm{H}$ ).

\section{Discussion}

From the exponential curve obtained for $\mathrm{CO}_{2}$ net assimilation rate, the saturation of net $\mathrm{CO}_{2}$ photosynthesis occurred at higher concentrations of about $1200 \mu \mathrm{mol} \mathrm{m}^{-2} \mathrm{~s}^{-1}$ PFDP, which may be due to limitation of carboxylation reactions (Taiz and Zeiger, 2013). It is possible note that plants treated with $T$. occidentalis $6 \mathrm{CH}$ have decreased the stomatal conductance. Silva (2005), by applying Suphur $6 \mathrm{CH}$ on soil under the plants Sphagneticola trilobata (L.) Pruski, found that $\mathrm{CO}_{2}$ assimilation tended to be lower in plants subjected to homeopathic medicine, attributing the effect to a possible pathogenesis that Sulphur is capable of causing, since when applied Appis mellifica, we obtained results in the increase of $\mathrm{CO}_{2}$ assimilation in the control. In this study, plants subjected to the homeopathic treatment of $T$. occidentalis $6 \mathrm{CH}$ tended to decrease in $A$ and $g_{s}$, though this hypothesis cannot be generalized, since the tomato plants in this study showed no apparent aspect of pathogenesis.

The literature reports that when the plant is subjected to stress conditions, they respond by producing compounds that can lead to stomatal closure, such as abscisic acid and reactive oxygen species to induce increasing in $\mathrm{Ca}^{2+}$ concentration in the cytosol of the kept cells, leading to stomatal closure (Klüsener et al., 2002). This dynamization can be not the ideal, and when it is happens, the homeopathy show negligible results (BONATO; SILVA, 2003). Although the $6 \mathrm{CH}$ treatments had lower mean values for $A$, $g_{s}, C i$ and $E$, the homeopathic treatment presented greater efficiency in water use. Therefore, nematode inoculated plants when treated with $T$. occidentalis $6 \mathrm{CH}$ were more efficient at fixing $\mathrm{CO}_{2} \mu \mathrm{mol}$ per $\mathrm{mmol}$ of water by transpiration rate. Plants infected with nematodes and without $T$. occidentalis $6 \mathrm{CH}$ had similar WUE rates of healthy plants without inoculation, demonstrating efficacy of homeopathic treatment in relation to this variable. When there is a decrease in stomatal conductance, transpiration rate also decreases, and this decrease is greater than the decrease in net photosynthetic rate (Habermann et al., 2003).

The effect of $i W U E$ also corroborates with the results of $W U E$, in this way the use of $T$. occidentalis $6 \mathrm{CH}$ also shows efficiency in the fixation of $\mathrm{CO}_{2}$ by the stomatal opening, 
that is, for each mols of water used in the stomatal turmoil there were larger amounts of umols of $\mathrm{CO}_{2} \mathrm{~m}^{-2} \mathrm{~s}^{-1}$ fixed compared to Control and $\mathrm{H} 2 \mathrm{O}$ treatments. According to Martin et al. (1994), leaf photosynthetic rate and water use efficiency are controlled by stomatal properties and by the anatomical characteristics of the leaves. Since WUE expresses the production of biomass per unit of water, leaf characteristics can be important when plants grow in waterlimited environments (Van Den Boogaard et al., 1997).

The diffusion of $\mathrm{CO}_{2}$ occurs through the stomatal opening increasing its intercellular concentration, however the greater stomatal opening provided by the increase in photon densities, the higher the net assimilation rate of $\mathrm{CO}_{2}$. In the present study the ratio of increase of $A$ and decrease of $C i$, were proportional resulting in similar means for $A C i$. The instantaneous carboxylation capacity was not influenced by nematode infection in roots of nematode plants.

The loss of water in the form of vapor by the plants through the leaves provoke the foliar cooling, preventing greater losses of photosynthetic efficiency, such as the activity of the rubisco enzyme (Taiz and Zeiger, 2013). Plants inoculated with nematodes and treated with $T$. occidentalis $6 \mathrm{CH}$ showed higher leaf temperature means, this behavior is directly related to leaf cooling due to transpiratory rate of Control and $\mathrm{H} 2 \mathrm{O}$ treatments.

In Figure $2 \mathrm{~A}$ is possible to realize that healthy plants require less $\mu \mathrm{mol} \mathrm{m}^{-2} \mathrm{~s}^{-1}$ of photons to start the photosynthesis process. Habermann et al. (2003) found a smaller light compensation point in healthy citrus plants when compared to plants with CVC (citrus variegated chlorosis), a disease that leads to the obstruction of plants' vascular system. These authors concluded that an increase of irradiance on the light compensation point results in increased photosynthesis, indicating that photosynthesis is limited by the amount of available light and that the PPFD saturation curve is limited by the electron transport rate and the regeneration of the rubisco enzyme.

Apparently, $T$. occidentalis $24 \mathrm{CH}$ inhibited the negative effect of nematodes on stomatal conductance, since plants treated with this substance showed a similar behavior to healthy plants. The behavior observed in plants treated with water can be the result of a hormonal imbalance promoted by nematode infection. The stomatal behavior can be affected by both climatic factors such as hormonal factors (Dodd, 2003).

Pathogens are capable of interfering with hormonal changes promoted by the plant as a defense strategy and produce phytohormones as an infection strategy (RobertSeilaniantz et al., 2007). Root knot nematodes, such as $M$. incognita, are capable of producing conjugates of auxin and cytokinin, which can interfere with the hormonal balance of plant cells (De Meutter et al., 2005).

At the time the nematode reaches the vascular bundles and during the early stages of the nematode-plant interaction, Lohar et al. (2004) found peaks of cytokinin in transgenic plants of Lotus japonicus L., although it was unclear whether this increase in cytokinin was due to nematode secretion or to the sensitivity of the host. In addition, Bird and Loveys (1980) found differences in cytokinin content in tomato plants infected with Meloidogyne javanica (Treub) Chitwood when compared to control plants, especially in periods of change in developmental stage of the nematode ( $\mathrm{J} 2$ to $\mathrm{J} 3$ and $\mathrm{J} 4$ ).
However, De Meutter et al. (2003) detected the presence of cytokinins in exudates $M$. incognita in vitro experiment, zeatin and benzyladenine being the most prominent forms, noting that this hormone may be important in the activation of cell cycle and induction of feeding site. To Farquhar and Sharkey (1982), the increased supply of cytokinins in roots could lead to an increase in photosynthesis, stimulating chlorophyll formation and protein synthesis, and at the same time, promoting stomatal opening. In relation to auxin, there is evidence that this hormone can promote stomatal closure (Dodd, 2003). The cytokines produced in the root are transported through the xylem to the shoot of the plants to regulate their growth (Takey et al., 2001). Photosynthetic pigments present in plants, such as chlorophyll and carotenoids, are essential for photosynthesis, capturing solar radiation and initiating the photochemical step by fixing $\mathrm{CO}_{2}$ and producing carbohydrates (Kluge et al., 2015). According to Bird (1974), nematodes can use these growth hormones (cytokine and auxin) for their own purpose and require a certain level in their host plants for their growth and reproduction.

Messchmidt (2013) reported that a peach graft susceptible to $M$. javanica presented the highest rate of net $\mathrm{CO}_{2}$ assimilation in the first 60 days after grafting, which was statistically similar to the rate at day 90,120 and 150, and may be an initial response to nematode infection. The measurements of this study were performed after 14, 15, and 17 days of infection, even without visual symptoms of the disease. These results corroborate with the results of this study, where plants infected with $M$. incognita and no treated showed highest rate of $\mathrm{CO}_{2}$ assimilation that plants without nematode or with and treated with $24 \mathrm{CH}$ and $50 \mathrm{CH}$ (Figure 2C).

Abrão and Mazzafera (2001) observed that cotton plants, Acala (susceptible cultivar), inoculated with $5.000 \mathrm{~J} 2$ and eggs of $M$. incognita showed increase in photosynthesis, chlorophyll and sugar content compared with plant no inoculated, and the authors suggest that it can be related with the increased demand for photoassimilates in plants attacked by nematodes. In this work, $T$. occidentalis $24 \mathrm{CH}$ inhibited this effect, and the photosynthesis rate of treated plants were statistically similar that plants without nematode. According with Bonato (2007), when the correct homeopathic medicine is applied in the plant that is suffering abiotic or biotic stress, the response will be the reduction of harmful effects and re-establishment of plant health, in biochemical and energy levels.

Other works confirm that the homeopathy is able to promote change in biology of plants, as exposed by Panda et al. (2013), where the potentised homeopathic Arsenicum album e Baryta carbonica increased in chlorophyll a, chlorophyll $b$ and chlorophyll total. Cotton plants treated with homeophatic drugs suffering influence in their genetic process, as acceleration of the germinative process, shortening cultivation period, increase in yeald and quality of product (Gangar, 2007).

The increase in photosynthesis can be related both to increased stomatal opening, which allows greater $\mathrm{CO}_{2}$ diffusion into the intercellular spaces, as may be associated with increased carboxylation efficiency (Machado et al., 2005). Tahery (2012a) found an increase in stomatal conductance in Hibiscus cannabinus L. plants infected with $M$. incognita after 60 and 90 days of inoculation. 
Higher rates of $E$ may decrease water use efficiency, this behavior can be observed by the greater stomatal opening in plants with nematodes without homeopathic treatment $(24 \mathrm{CH})$. This effect caused higher transpiration rates, decreasing WUE. According Blum (2009) the water use efficiency is important to indicate the yield under stress conditions. Messchimidt (2013) found higher water use efficiency rates in healthy peach grafts than in peach grafts infected with $M$. incognita. Tahery (2012b) studied the effect of the nematode $M$. incognita in water responses of $H$. cannabinus and found similar results: plants inoculated with nematodes had the lowest WUE and IWUE values, when compared to healthy plants after 30, 60 and, 90 days of inoculation. Treatments with $6 \mathrm{CH}$ T. occidentalis dynamics induced stomatal closure, resulting in lower transpiration rate and higher leaf temperature, as well as $24 \mathrm{CH}$ and $50 \mathrm{CH}$ treatments.

\section{Material and Methods}

\section{Treatments}

T. occidentalis was obtained in a homeopathic pharmacy in the potency of $6 \mathrm{CH}$ (according to Hahnemann's centesimal scale) and diluted to $24 \mathrm{CH}$ and $50 \mathrm{CH}$. A water control (with nematode and untreated) and an absolute control (without nematode and untreated) were used. This method consisted in, 1 part of homeopathic preparation diluted in 99 parts of $30 \%$ ethanol, followed by 100 successions, in accordance with the Brazilian Homeopathic Pharmacopoeia (FHB, 2011).

\section{Inoculum of Meloidogyne incognita}

The pure population of this nematode was collected from tomato roots cultivated in green house. The eggs and second stage juveniles (J2) were obtained with Boneti and Ferraz (1981) methodology.

\section{Experiment deployment}

Santa Clara' tomato seeds were sown in polystyrene trays containing commercial substrate to obtain seedlings. After 25 days of sowing, seedlings were transplanted to plastic pots $(2 \mathrm{~L})$ containing a sterilized mixture of soil, sand and organic compound (2:2:1). Sterilization was performed by autoclaving at $120^{\circ} \mathrm{C}$ ( $1 \mathrm{~atm}$.) for $1 \mathrm{~h}$.

At the time of transplanting, the root system of the tomato seedlings cultivar 'Santa Clara' was dipped in $0.1 \%$ of treatment solution $(1 \mathrm{~mL}$ of solution diluted in $1 \mathrm{~L}$ of distilled water) before seedlings were planted in the pots. Seven days after planting, seedlings were inoculated with $M$. incognita suspension containing 4350 eggs and $700 \mathrm{~J} 2$. Subsequently, plant shoots were weekly sprayed with the different treatments. The infestation level (egg mass rate) was evaluated after 40 days of inoculation with nematodes, according to Taylor and Sasser (1978) methodology.

\section{Gas exchange evaluation}

Gas exchange was measured on full sun days, between 9:00 am and 11:00 am, using an infrared gas analyzer (IRGA) portable photosynthetic system (Li-6400XT, LI-COR, Lincoln, Nebraska, USA). Gas exchange measurements were done prior to nematode inoculation and five, eight, and 13 days after inoculation. Measurements were performed in $6 \mathrm{~cm}^{2}$ of the second fully expanded leaf that was exposed to sunlight. The following parameters were determined: $A-\mathrm{CO}_{2}$ net assimilation rate $\left(\mu \mathrm{mol} \mathrm{CO}_{2} \mathrm{~m}^{-2} \mathrm{~s}^{-1}\right), E$ - transpiration rate ( $\left.\mathrm{mmol} \mathrm{H} \mathrm{O} \mathrm{m}^{-2} \mathrm{~s}^{-1}\right), g_{s}$ - stomatal conductance $\left(\mathrm{mol} \mathrm{m}^{-2} \mathrm{~s}^{-1}\right)$, and $\mathrm{Ci}$ - internal $\mathrm{CO}_{2}$ concentration $\left(\mu \mathrm{mol} \mathrm{CO}_{2} \mathrm{~mol}^{-1}\right)$. Air temperature within the chamber of the photosynthetic system was $21.63{ }^{\circ} \mathrm{C}$ prior to inoculation and 28.56, 25.45, and $29.95{ }^{\circ} \mathrm{C}$ after five, eight, and 13 days of inoculation, respectively. Vapor pressure deficit (VPD) was, respectively, $1.46,2.71,2.22$, and $2.36 \mathrm{kPa}$, whereas relative humidity was, respectively, $38.25,39.43,44.71$, and $43.08 \%$. In addition, the photosynthetic response curve to light was measured in plants receiving the $6 \mathrm{CH}, 24 \mathrm{CH}, 50 \mathrm{CH}$, water control, and absolute control treatments. The response curve was measured 14,15 , and 17 days after inoculation.

The $\mathrm{CO}_{2}$ liquid uptake rate $(A)$ response curve for different photosynthetic photon flux density (PPFD) was carried out using an artificial red light emitting diode (LED) controlled by a sensor located within the leaf chamber. The curve was obtained by varying the PPFD from $1800 \mu \mathrm{mol} \mathrm{m}^{-2} \mathrm{~s}^{-1}$ to zero and measurements started at $400 \mu \mathrm{mol} \mathrm{mol}^{-1}$ of $\mathrm{CO}_{2}$. The $A$ response curve for PPFD was adjusted according to the equation of Prado and Moraes (1997). The other parameters were adjusted with the model that provided the highest correlation coefficient value. The following ratios were also calculated: water use efficiency (WUE) $(A / E, \mu \mathrm{mol} \mathrm{CO} 2 / \mathrm{mmol}$ $\left.\mathrm{H}_{2} \mathrm{O} \mathrm{m}^{-2} \mathrm{~s}^{-1}\right)$, carboxylation capacity $(A C i)\left(\mathrm{A} / \mathrm{Ci}, \mu \mathrm{mol} \mathrm{CO}_{2} \mathrm{~m}^{-2}\right.$ $\left.\mathrm{s}^{-1} / \mu \mathrm{mol} \mathrm{CO}_{2} \mathrm{~mol}^{-1}\right)$, and intrinsic water use efficiency (IWUE) $\left(\mathrm{A} / \mathrm{g}_{\mathrm{s}}, \mu \mathrm{mol} \mathrm{CO} \mathrm{CO}_{2} / \mathrm{mol} \mathrm{m}^{-2} \mathrm{~s}^{-1}\right)$ (Zhang et al., 2001).

\section{Experimental design and data analysis}

Experiments were conducted in a greenhouse using a randomized block design with four replications. Averages of egg mass (infestation level) was submitted to Tukey test. Averages of the PPFD response curves were subjected to regression analysis. To analyze the interaction between plant treatment and PPFD response curve, a split analysis was performed in which the different treatments were analyzed within each level of photosynthetic photon flux density. It was used the statistical program SISVAR (Ferreira, 2011).

\section{Conclusion}

Gas exchange measurements at specific time did not show a significant difference between treatments. The most important physiological changes observed in tomato plants infected with $M$. incognita were the increase in net photosynthesis and in the carboxylation capacity, as seen in the response curve to light. Treatment with the homeopathic plant $T$. occidentalis $24 \mathrm{CH}$ inhibited the increase in $\mathrm{CO}_{2}$ fixation in tomato plants inoculated with $M$. incognita, resulting in a behavior similar to that of healthy plants, independent of the photon density.

\section{Acknowledgments}

To CAPES for the scholarship of first author, Fundação Araucária for financial support (CV 123/2014) and CNPq for the productivity scholarship provided to JRS. 


\section{References}

Abrão MM, Mazzafera P (2001) Efeitos do nível de inóculo de Meloidogyne incognita em algodoeiro. Bragantia. 60:19-26.

Bird AF (1974) Plant response to root-knot nematode. Ann Rev of Phytopathol. 12:69-85.

Bird AF, Loveys BR (1980) The involvement of cytokinins in a host-parasite relationship between the tomato (Lycopersicon esculentum) and a nematode (Meloidogyne javanica). Parasitology. 80:497-505.

Bonato CM (2007) Homeopatia em modelos vegetais. Cultura Homeopática. 6:24-28.

Bonato CM, Silva EP (2003) Effect of the homeopathic solution Sulphur on the growth and productivity of radish. Acta Sci., Agron. 25: 259-263.

Bonetti JIS, Ferraz S (1981) Modificações do método de Hussey \& Barker para extração de ovos de Meloidogyne exigua em raízes de cafeeiro. Fitopatol Bras. 6:553.

Blum A (2009) Effective use of water (EUW) and not water-use efficiency (WUE) is the target of crop yield improvement under drought stress. Field Crops Res. 112:119-123.

Castagnone-Sereno P, Danchin EGJ, Perfus-Barbeoch L, Abad P (2013) Diversity and evolution of root-knot nematodes, genus Meloidogyne: new insights from the genomic era. Ann Rev of Phytopathol. 51: 203-220.

De Meutter J, Tytgat T, Prinsen E, Gheysen G, Van Oncklen H, Gheysen $G$ (2003) Production of auxin and related compounds by the plant parasitic nematodes Heterodera schachtii and Meloidogyne incognita. Commun Agric Appl Biol Sci. 70:51-60.

Dodd IC (2003) Hormonal interactions and stomatal responses. J Plant Growth Regul. 22:32-46.

Farquhar GD, Sharkey TD (1982) Stomatal conductance and photosynthesis. Annu Rev Plant Physiol. 33: 317-345

Farmacopéia Homeopática Brasileira - FHB (2011) Métodos de preparações das formas farmacêuticas derivadas. 3. ed. São Paulo: Andrei. 364 p.

Ferreira DF (2011) Sisvar: a computer statistical analysis system. Cienc Agrotecnol. 35:1039-1042.

Gangar HU (2007) Effects of homeopathic drugs on cotton plants. Nat Prod Rad. 6:138-141.

Habermann G, Machado EC, Rodrigues JD, Medina CL (2003) $\mathrm{CO}_{2}$ assimilation, photosynthetic light response curves, and water relations of 'Pêra' sweet orange plants infected with Xylella fastidiosa. Braz J Plant Physiol. 15:79-87.

Karssen G, Moens M (2006) Root-knot nematodes. In: Perry RN, Moens $M$ (eds) Plant Nematology. Wallingford, United Kingdom: CAB International. 59-88.

Kluge RA, Tezzoto-Uliana JV, Da Silva PPM (2015). Physiological and environmental aspects of photosynthesis. Rev Virtual Quim. 7:56-73.

Klüsener B, Young JJ, Murata Y, Allen GJ, Mori IC, Hugouvieux V, Schroeder JI (2002) Convergence of calcium signaling pathways of pathogenic elicitors and abscisic acid in arabidopsis guard cells. Plant Physiol. 130: 2152-2163.

Lohar DP, Schaff JE, Laskey JG, Kieber JJ, Bilyeu KD, Bird DM (2004) Cytokinins play opposite roles in lateral root formation, and nematode and Rhizobial symbioses. Plant J. 38:203-214.

Messchmidt AA (2013) Physiological responses induced by water stress and infection by Meloidogyne javanica (Treub) Chitwood on rootstocks of Prunus spp. Masters Dissertation, Federal University of Pelotas, Pelotas, RS, BR. 68p.
Mioranza TM, Stangarlin, JR, Müller MA, Coltro-Roncato S Inagaki AM, Meinerz CC, Estevez RL, Swarowsky RA, Schons $\mathrm{BC}$, Kuhn OJ (2017) Control of Meloidogyne incognita in tomato plants with highly diluted solutions of Thuya occidentalis and their effects on plant growth and defense metabolismo. Semina: Ciênc Agrár. 38:2187-2200.

Panda SS, Mohanty SS, Dhal NK (2013) Effects of potentised homeopathic medicines on the germination, growth and photosynthetic activity of Pisum sativum L. Recent Res Sci Technol. 5:11-14.

Prado CHBA, Moraes JAPV (1997) Photosynthetic capacity and specific leaf mass in twenty wood species of Cerrado vegetation under field conditions. Photosynthetica. 33:103 112.

Robert-Seilaniantz A, Navarro L, Bari R, Jones JD (2007) Pathological hormone imbalances. Curr Opin Plant Biol. 10:372-379.

Sarkar T, Konar A, Sukul NC, Sukul A, Datta P, Sutradhar A (2017) High dilution of mercuric chloride increases water permeation, chlorophyll content and growth in germinating seeds of cowpea Vigna unguiculata (I.) Walp. Environ Ecol. 35:3067-3071.

Silva MRB (2005) Assimilation of $\mathrm{CO}_{2}$ in plant of Sphagneticola trilobata (L.) Pruski negotiated with prepared homeopathic. Master Dissertation, Federal University of Viçosa, Viçosa, MG, BR. 54p.

Sukul NC, Chakraborty I, Sukul A (2013) Potentized Cina reduces root-knot nematode in infestation of cucumber and the antinematode effect is transmitted through water. IJHDR. 12:133-4.

Swarowsky RA, Stangarlin JR, Kuhn OJ, Estevez RL, Mioranza TM, Müller MA (2014) Influence of high dilutions of Cina for the control of Meloidogyne incognita in tomato plants. Am J Plant Sci. 5:3695-3701.

Tahery Y (2012a). Measurement of gas exchange characteristics and stomatal conductance of Hibiscus cannabinus infected with Meloidogyne incognita. Ann Biol Res. 3:280-290.

Tahery Y (2012b). Effect of root knot nematode (Meloidogyne incognita) on water responses of kenaf (Hibiscus cannabinus L.). Ann Biol Res. 3:222-230.

Taiz L, Zeiger E (2013) Fisiologia vegetal. 5th Ed. Porto Alegre: Artmed, 2013.

Takey K, Sakakibara H, Taniguchi M, Sugiyama T (2001) Nitrogen-dependent accumulation of cytokinins in root and the translocation to leaf: implication of cytokinin species that induces gene expression of maize response regulator. Plant Cell Physiol. 42: 85-93.

Taylor AL, Sasser JN (1978) Biology, Identification and Control of Root-Knot Nematodes (Meloidogyne sp.). Raleigh, North Carolina State University, USA.

Toledo MV, Stangarlin JR, Bonato CM (2011) Homeopathy for the control of plant pathogens. Science Against Microbial Pathogens: Communicating Current Research and Technological Advances. 2:1063-1067.

Van Den Boogaard R, Alewijnse D, Veneklaas EJ, Lambers H (1997) Growth and water-use efficiency of 10 Triticum aestivum cultivars at different water availability in relation to allocation of biomass. Plant Cell Environ. 20:200-210.

Zhang S, Li Q, Ma K, Chen L (2001) Temperature-dependent gas exchange and stomatal/non-stomatal limitation to $\mathrm{CO}_{2}$ assimilation of Quercus liaotungensis under midday higher irradiance. Photosynthetica. 39:383-388. 